\title{
Global methylation and promoter-specific methylation of the P16,SOCS-1,E-cadherin, P73 and SHP-1 genes and their expression in patients with multiple myeloma during active disease and remission
}

\author{
DÉBORAH MARTÍNEZ-BAÑOS ${ }^{1}$, BEATRÍZ SÁNCHEZ-HERNÁNDEZ ${ }^{2}$, \\ GUADALUPE JIMÉNEZ ${ }^{1}$, GEORGINA BARRERA-LUMBRERAS ${ }^{1}$ and OLGA BARRALES-BENÍTEZ ${ }^{1}$ \\ Departments of ${ }^{1}$ Hematology and Oncology and ${ }^{2}$ Genetics, National Institute of Medical Science and \\ Nutrition Salvador Zubiran, Mexico City, Tlalpan 14080, Mexico
}

Received September 11, 2015; Accepted October 21, 2016

DOI: 10.3892/etm.2017.4274

\begin{abstract}
Tumor suppressor gene promoter $\mathrm{CpG}$ island methylation is a well-recognized mechanism in cancer pathogenesis, but its role in multiple myeloma (MM) is controversial. The present study investigated the methylation status and expression of P16, suppressor of cytokine signaling 1 (SOCS-1), P73, $E$-cadherin and Src homology region 2 domain-containing phosphatase 1 (SHP-1), as well as global methylation in patients with MM during active disease and remission. Bone marrow samples were obtained from 43 patients at the Multiple Myeloma Clinic, Instituto Nacional de Ciencias Médicas y Nutrición Salvador Zubirán (Mexico City, Mexico) during active disease and remission. Methylation-specific polymerase chain reaction and ELISA were performed on bisulfite-treated or untreated DNA to determine promoter-specific or genomic methylation, respectively. Gene expression was measured using reverse-transcription polymerase chain reaction. The results indicated that SOCS-1 methylation occurred more frequently during active disease than remission [29 vs. 3.2\% ( $\mathrm{P}=0.021)]$ and was associated with more advanced forms of the disease [international staging system (ISS) $3,16.67 \%$ vs. ISS $1,8.3 \%$ $(\mathrm{P}=0.037)$ ]. SHP -1 methylation during active disease was associated with a lower probability of survival at 39-month follow up (median), 52.5 vs. $87.5 \%(\mathrm{P}=0.025)$. The percentage of methylation was associated with active disease at remission,
\end{abstract}

Correspondence to: Dr Déborah Martínez-Baños, Department of Hematology and Oncology, National Institute of Medical Science and Nutrition Salvador Zubiran, Avenida Vasco de Quiroga 15, Colonia Belisario Domínguez Sección XVI, Mexico City, Tlalpan 14080 Mexico

E-mail: deborahmtzbanos@hotmail.com

Key words: methylation, multiple myeloma, tumor suppressor genes, remission, suppressor of cytokine signaling 1, Src homology region 2 domain-containing phosphatase-1, overall survival but this was not significant. Global hypomethylation at remission was a negative predictor factor for overall survival (OS). The results indicated that methylated P16, SOCS-1 and SHP-1 were associated with clinical variables of poor prognosis in MM, likewise the persistence of global hypomethylation at remission. The negative impact on OS of global hypomethylation at remission must be confirmed in a larger sample. Future studies are necessary to investigate whether patients with global hypermethylation at remission should receive more aggressive treatments to improve their OS.

\section{Introduction}

Multiple myeloma (MM) is a malignant disease of complex etiology, characterized by the abnormal proliferation of plasma cells with a concomitant increase of monoclonal immunoglobulin in serum or urine, and immune deficiency. Patients with MM present with anemia, hypercalcemia, renal impairment and/or bone disease $(1,2)$. Promoter hypermethylation as the mechanism of transcriptional silencing of a number of genes has been demonstrated in samples from the bone marrow and peripheral blood of patients with MM and in MM cell lines, although the published results and their interpretation have been inconsistent $(3,4)$. The functional suppression of genes achieved by hypermethylation of $\mathrm{CpG}$-enriched sites, known as $\mathrm{CpG}$ islands, at the promoters and first exons is a mechanism associated with the development of cancer in mammals (5-7). $\mathrm{CpG}$ islands are found in $\sim 40 \%$ of mammalian promoters, particularly housekeeping and tumor suppressor genes (8). Hypermethylation, which involves the enzymatic addition of a methyl group to the fifth position of the deoxycytidine residue in each affected $\mathrm{CpG}$ dinucleotide $(6,7,9)$, leads to chromatin remodeling. This results in gene silencing and has been associated with cancer development through the inactivation of tumor suppressor genes (10-16). Unlike DNA sequence alterations, epigenetic modifications, such as DNA methylation, are dynamic and reversible with proven therapeutic implications (17-19). Furthermore, this method of deregulating functional pathways is more straightforward and therefore 
more likely to be effective than generating mutations or chromosomal aberrations (17). The genes most frequently reported as being hypermethylated in MM include the cell cycle inhibitors $P 15$ and $P 16(4,20,21)$, suppressor of cytokine signaling 1 (SOCS-1) (22), E-cadherin, which promotes cellular adhesion, and the tumor suppressor genes $P 73$ and Src homology region 2 domain-containing phosphatase 1 (SHP-1) (23). The expression of specific genes has been restored in vitro through the utilization of demethylating agents, including 5-aza-2'-deoxycytidine, 5-azacitidine and zelaburine (24,25). However, an alternate epigenetic mechanism for promoting tumorigenesis is possible. Global loss of DNA methylation occurs in genomic regions containing repetitive elements and retrotranposons, resulting in chromosomal instability, activation of transposable elements and transcriptional activation of oncogenes (15). The aims of the current study were to determine the promoter methylation status and expression levels of the genes P16, SOCS-1, E-cadherin, $P 73$ and SHP-1 in patients with MM at two different phases of the disease, active and remission. In addition, the present study aimed to determine the status of global DNA methylation and its association with clinical outcome in these patients.

\section{Materials and methods}

Patients. A total of 43 patients, including 20 males and 23 females (age range, 36-87 years) were recruited from the Multiple Myeloma Clinic at the Instituto Nacional de Ciencias Médicas y Nutrición Salvador Zubirán (Mexico City, Mexico) between November 2006 and December 2012. At the time of analysis, median follow-up time was 39 months (range, 5-89 months). Bone marrow samples were obtained from each patient at two different phases of the disease: Active (diagnosis or relapse) and remission; therefore, a total of 86 samples were collected. Patients were included if they had a symptomatic MM diagnosis according to the International Myeloma Working Group (IMWG) criteria (26). Patients were excluded if they had a history of previous malignant disease, a concomitant malignant disease or were currently prescribed any demethylating agents. The response criteria used were the standard IMWG Uniform Response Criteria (26). The present study was approved by the Ethics Committee of the Instituto Nacional de Ciencias Médicas y Nutrición Salvador Zubirán (Mexico City, Mexico) and was conducted in accordance with the guidelines stipulated in the Declaration of Helsinki. All enrolled patients signed an informed consent form.

Cluster of differentiation (CD) $138^{+}$purified plasma cells $(P C s)$. PCs were separated from bone marrow aspirate. Centrifugation on a ficoll gradient (27) was used to isolate total lymphocytes from the sample. Samples were centrifuged at $322 \mathrm{x}$ g for $30 \mathrm{~min}$ at room temperature. The lymphocytes were then incubated on ice for 30 min with CD138 magnetic beads (Miltenyi Biotec GmbH, Bergisch Gladbach, Germany). Cells were separated on a $\mathrm{LS}^{+}$MACs column (Miltenyi Biotec $\mathrm{GmbH}$ ) following incubation and eluted according to the manufacturer's protocol.

Methylation-specific polymerase chain reaction (MS-PCR). Genomic DNA was extracted from PCs using the DNeasy
Blood \& Tissue kit (Qiagen, Benelux B.V., Venlo, The Netherlands) according to the supplier's protocol. Extracted DNA was subjected to sodium bisulfite modification using an EpiTect Bisulfite Modification kit (Qiagen, Benelux, B.V.) according to the manufacturer's instructions. For each reaction, $1.5 \mu \mathrm{g}$ DNA was used. CpG methylated Jurkat genomic DNA (New England BioLabs Ltd., Ipswich, MA, USA) was used as the positive control and 5-Aza-dC-treated Jurkat Genomic DNA (New England BioLabs, Ltd.) was used as the negative control. Bisulfite-modified DNA was amplified using primer sets specific for unmethylated (U) and methylated (M) sequences in each gene. The MS-PCR was carried out in a final volume of $15 \mu \mathrm{l}$ using $15 \mathrm{ng}$ of bisulfite-modified DNA and $10 \mathrm{pmol}$ forward and reverse primers. The cycling conditions were: $95^{\circ} \mathrm{C}$ for $30 \mathrm{sec}, 30 \mathrm{sec}$ at the annealing temperature (Table I) and $72^{\circ} \mathrm{C}$ for $45 \mathrm{sec}$ for 40 cycles.

Primer sequences (Integrated DNA Technologies, Inc., Coralville, IA, USA) are presented in Table I. The resulting MS-PCR products underwent electrophoresis on 3\% agarose gels and were visualized with ethidium bromide staining. Each PCR reaction contained a water blank, a positive control and a negative control. A visible PCR product using the $\mathrm{U}$ set primers indicated the presence of unmethylated gene promoters and the presence of product using $\mathrm{M}$ set primers indicated the presence of promoter methylation. Samples that revealed no PCR product in either the unmethylated or methylated reactions indicated that an insufficient quantity of DNA was present in the sample following processing and sodium bisulfite modification. Each of the PCR amplifications was repeated at least once to confirm the result. The sensitivity of MS-PCR to detect methylated alleles in a background of unmethylated alleles was 1:1,000 (28). The percentage of methylation status for each gene at disease activity and remission was calculated.

RNA preparation and reverse-transcription PCR (RT-PCR). RNA was isolated from CD 138-enriched bone marrow cells using the RNeasy Mini kit (Qiagen, Benelux, B.V.) according to the manufacturer protocol. For cDNA synthesis, $1 \mu \mathrm{g}$ RNA was reverse transcribed in a $20-\mu 1$ volume reaction mixture, using a High-Capacity cDNA Reverse Transcription kit (Applied Biosystems; Thermo Fisher Scientific, Inc., Waltham, MA, USA). Primer sequences and conditions were as described in Table II. Each reaction was performed with $2 \mu \mathrm{l}$ cDNA template in a $15 \mu 1$ reaction mixture containing $7.5 \mu 12$ X HotStarTaq Plus PCR Master Mix (Qiagen, Benelux, B.V.) and $0.2 \mu \mathrm{M}$ each primer. The cycling conditions were $95^{\circ} \mathrm{C}$ for $30 \mathrm{sec} ; 30 \mathrm{sec}$ at the annealing temperature (Table II) and $72^{\circ} \mathrm{C}$ at $45 \mathrm{sec}$ for 40 cycles. The presence or absence of the amplified sequence was visualized using $3 \%$ agarose gel electrophoresis stained with ethidium bromide and examined under UV light. $\beta$-actin mRNA expression in each sample demonstrated the integrity of the target transcript of interest. PCR performed with DNA of the same patient or in the absence of cDNA, as controls, yielded negative results.

Global methylation. Global DNA methylation levels were measured using an ELISA kit (Methylamp Global DNA Methylation Quantification Ultra kit; P-1014B-96; Epigentek, Inc., Farmingdale, NY, USA). A total of $1 \mu 1$ DNA at a concentration of $100-\mathrm{ng} / \mathrm{ml}$ was added to strip wells that were 
Table I. Methylation specific primer sequences and conditions.

\begin{tabular}{|c|c|c|c|}
\hline Gene & Primer sequences & Annealing temp, ${ }^{\circ} \mathrm{C}$ & Size, bp \\
\hline \multicolumn{4}{|c|}{ E-cadh } \\
\hline M & $\begin{array}{l}\text { For 5'-TTAGGTTAGAGGGTTATCGCGT-3' } \\
\text { Rev 5'-TAACTAAAAATTCACCTACCGAC-3' }\end{array}$ & 56.3 & 116 \\
\hline $\mathrm{U}$ & $\begin{array}{l}\text { For 5'-TAATTTTAGGTTAGAGGGTTATTGT-3' } \\
\text { Rev 5'-CACAACCAATCAACAACACA-3' }\end{array}$ & 56.3 & 97 \\
\hline \multicolumn{4}{|l|}{ P73 } \\
\hline M & $\begin{array}{l}\text { For 5'-TTAGGTTAGTCGGGACGGAC-3' } \\
\text { Rev 5'-CCGAAAAAACCCCTATATCG-3' }\end{array}$ & 56.4 & 204 \\
\hline $\mathrm{U}$ & $\begin{array}{l}\text { For 5'-AGGTTAGTTGGGATGGATGT-3' } \\
\text { Rev 5'-AACTCCAAAAAAACCCCTATATCAC-3' }\end{array}$ & 56.4 & 206 \\
\hline \multicolumn{4}{|c|}{ P16INK4A } \\
\hline M & $\begin{array}{l}\text { For 5'-TTGGTAGTTAGGAAGGTTGTATCGC-3' } \\
\text { Rev 5'-TCCCTACTCCCAACCGCG-3' }\end{array}$ & 60 & 126 \\
\hline $\mathrm{U}$ & $\begin{array}{l}\text { For 5'-GGTAGTTAGGAAGGTTGTATTGT-3' } \\
\text { Rev 5'-TCCCTACTCCCAACCACA-3' }\end{array}$ & 60 & 124 \\
\hline \multicolumn{4}{|c|}{$S H P-1$} \\
\hline M & $\begin{array}{l}\text { For 5'-TTTTGTTGATGTTTATTTCGACGT-3' } \\
\text { Rev 5'-GAAAATCCTCACACCTTACGAA-3' }\end{array}$ & 56 & 159 \\
\hline $\mathrm{U}$ & $\begin{array}{l}\text { For 5'-GTTTTGTTGATGTTTATTTTGATGT-3' } \\
\text { Rev 5'-ACCAAAAATCCTCACACCTTACA-3' }\end{array}$ & 56 & 162 \\
\hline \multicolumn{4}{|c|}{ SOCS-1 } \\
\hline M & $\begin{array}{l}\text { For 5'-GTTCGGTTTCGTTTAGTTTTCGAGG-3' } \\
\text { Rev 5'-ACCCCGACCGACCGCGATCTC-3' }\end{array}$ & 62 & 139 \\
\hline $\mathrm{U}$ & $\begin{array}{l}\text { For 5'-GTTTGGTTTTGTTTAGTTTTTGAGG-3' } \\
\text { Rev 5'-ACCCCAACCAACCACAATCTC-3' }\end{array}$ & 62 & 139 \\
\hline
\end{tabular}

E-cadh, E-cadherin; P16INK4A, P16; SHP-1, Src homology region 2 domain-containing phosphatase-1; SOCS-1, suppressor of cytokine signaling; M, Methylated; U, Unmethylated.

Table II. Reverse transcription polymerase chain reaction primer sequences and conditions.

\begin{tabular}{|c|c|c|c|}
\hline Gene & Primer sequences & Annealing Temp, ${ }^{\circ} \mathrm{C}$ & Size, bp \\
\hline$\beta$-actin & $\begin{array}{l}\text { For 5'-GCTCGTCGTCGACAACGGCTC-3' } \\
\text { Rev 5'-CAAACATGATCTGGGTCATCTTCTC-3' }\end{array}$ & 60.2 & 353 \\
\hline$E$-cadh & $\begin{array}{l}\text { For 5'-GGTCTGTCATGGAAGGTGCTC-3' } \\
\text { Rev 5'-CAGGATCTTGGCTGAGGATGG-3' }\end{array}$ & 61.5 & 124 \\
\hline P73 & $\begin{array}{l}\text { For 5'-CCACGAGCCTACCATGCTTTAC-3' } \\
\text { Rev 5'-GGCACTGCTGAGCAAATTGA-3' }\end{array}$ & 56.5 & 314 \\
\hline P16INK4A & $\begin{array}{l}\text { For 5'-GGGGGCACCAGAGGCAGT-3' } \\
\text { Rev 5'-GGTTGTGGCGGGGGCAGTT-3' }\end{array}$ & 63.1 & 159 \\
\hline$S H P-1$ & $\begin{array}{l}\text { For 5'-CGAGGTGTCCACGGTAGCTT-3' } \\
\text { Rev 5'-CCCCTCCATACAGGTCATAGAAAT-3' }\end{array}$ & 61.0 & 139 \\
\hline SOCS-1 & $\begin{array}{l}\text { For 5'-CAGGTGGCAGCCGACAATGC-3' } \\
\text { Rev 5'-CCGCCGTCGGGGCTCTG-3' }\end{array}$ & 64.3 & 52 \\
\hline
\end{tabular}

E-cadh, E-cadherin; P16INK4A, P16; SHP-1, Src homology region 2 domain-containing phosphatase-1; SOCS-1, suppressor of cytokine signaling.

specifically treated to have a high DNA affinity. Samples were incubated at $37^{\circ} \mathrm{C}$ for 90 min followed by the introduction of capture and detection monoclonal antibodies against 5-methylcytosine (5-mC) and 5-hydroxymethylcytosine, which were provided with the kit. The absorbance was read at $450 \mathrm{~nm}$. Paired samples (active/remission) from each patient 
Table III. Baseline characteristics of the patients.

\begin{tabular}{|c|c|}
\hline Characteristics & Descriptive statistics \\
\hline Age, years: Median (range) & $60(36-87)$ \\
\hline Male gender: no. $(\%)$ & $20(46.5)$ \\
\hline \multicolumn{2}{|l|}{ Durie-Salmon Stage: no. (\%) } \\
\hline I & $3(7.1)$ \\
\hline II & $4(9.5)$ \\
\hline III & $35(83.3)$ \\
\hline \multicolumn{2}{|l|}{ ISS: no. (\%) } \\
\hline I & $11(27.5)$ \\
\hline II & $13(32.5)$ \\
\hline III & $16(40)$ \\
\hline \multicolumn{2}{|l|}{ Type of myeloma: no. (\%) } \\
\hline $\operatorname{IgG}$ & $16(47.1)$ \\
\hline $\operatorname{Ig} \mathrm{A}$ & $10(29.4)$ \\
\hline Light chain & $7(20.6)$ \\
\hline Biclonal & $1(2.9)$ \\
\hline \multicolumn{2}{|l|}{ Hemoglobin } \\
\hline Median (range) g/dl & $11.5(6.2-15.6)$ \\
\hline \multicolumn{2}{|l|}{ Creatinine } \\
\hline Median (range) mg/dl & $9.4(4.8-8.56)$ \\
\hline \multicolumn{2}{|l|}{ Calcium } \\
\hline Median (range) mg/dl & $9.1(9-13.6)$ \\
\hline Lytic lesions: no. (\%) & $32(74.4)$ \\
\hline Plasmacytoma: no. (\%) & $18(41.9)$ \\
\hline Osseous: no. (\%) & $9(21.4)$ \\
\hline Extramedullar: no. (\%) & $9(20.9)$ \\
\hline
\end{tabular}

ISS, international staging system; IgG, immunoglobulin G; IgA, immunoglobulin A.

were analyzed simultaneously on the same plate in neighboring positions to decrease the possibility of experimental variance and each sample was run in duplicate. A standard curve was generated from the plot of optical density (OD) values vs. the quantity of positive control [methylated polynucleotide containing $50 \% 5-\mathrm{mC}$ at each concentration point] using Excel 2013 version 15.0 (Microsoft Corporation, Redmond, WA, USA) and used to quantify the percentage of methylated DNA 5-mC in each total DNA sample. Results were considered to be hypomethylated if they were below the median for all samples. The percentage of DNA hypomethylation in disease activity and remission was calculated. The associations of global methylation between groups were calculated by Spearman's correlation coefficient.

Statistical analysis. Continuous variables were presented as medians and ranges; categorical variables were presented as frequencies and proportions. Fisher's exact test was used to estimate statistical significance between proportions. The mean was analyzed by independent-sample t-test. Gene methylation status and expression were compared for the same subject in active and remission states using the McNemar paired $\chi^{2}$ test. In addition, continuous variables measured in active vs. remission or with vs. without methylation were compared with the paired t-test. Survival analysis was performed using the Kaplan-Meier procedure. Survival-related prognostic factors were analyzed with the Cox proportional hazards regression model. Associations of global methylation between groups were evaluated by Spearman's correlation coefficient. OS was calculated from the time of diagnosis until mortality or the last date in which it was ascertained that the patient was alive. Progression-free survival (PFS) was calculated from the time of treatment initiation to the date of progression or relapse. $\mathrm{P}<0.05$ was considered to indicate a statistically significant difference. Data were analyzed using SPSS version 21.0 software (IBM SPSS, Inc., Armonk, NY, USA).

\section{Results}

Patient demographics and clinical features. Of the 43 patients enrolled in the present study, 28 (65\%) were diagnosed when the first sample was taken. At the time of the analysis, median follow-up time was 39 months (range; 5-89 months). Demographic and clinical characteristics were similar to other reported MM series $(29,30)$, with the exception of a slight increase in the frequency of the light chain myeloma sub-type. Most patients at diagnosis were at an advanced stage of the disease, with $72.5 \%$ in categories II and III of the International Staging System (ISS; Table III) (31).

Treatment and clinical response. Various treatments were received by the patients included in the current study. Of the 43 patients, $20(46.5 \%)$ received a combination based on alkylating agents $[0.25 \mathrm{mg} / \mathrm{kg}$ melphalan (Alkeran; GlaxoSmithKline plc, Brentford, UK) and $100 \mathrm{mg}$ prednisone daily for four days every four weeks, or $900 \mathrm{mg} /$ $\mathrm{m}^{2}$ cyclophosphamide intravenously on day 1 and $40 \mathrm{mg}$ dexamethasone orally on days 1-4, 9-12 and 17-20 every 4 weeks], $12(27.9 \%)$ received a combination that included thalidomide $[0.25 \mathrm{mg} / \mathrm{kg}$ melphalan and $100 \mathrm{mg}$ prednisone daily for four days every four weeks plus $100 \mathrm{mg}$ daily thalidomide (Talizer; Serral Laboratories; SOMAR, Mexico City, Mexico) or $100 \mathrm{mg}$ thalidomide daily plus $40 \mathrm{mg}$ dexamethasone on days 1-4, 9-12 and 17-20 every four weeks), $7(16.3 \%)$ received a combination with bortezomib [1.5 mg/ $\mathrm{m}^{2}$ bortezomib (Velcade; Janssen Pharmaceutica, Beerse, Belgium) subcutaneously on days 1, 8, 15 and 22, $300 \mathrm{mg}$ / $\mathrm{m}^{2}$ cyclophosphamide intravenously on days $1,8,15$ and 22 , and $40 \mathrm{mg}$ dexamethasone orally on days 1-4, 9-12 and 17-20 for two cycles and $40 \mathrm{mg}$ on days $1,8,15$ and 22 thereafter], $2(4.7 \%)$ received an infusional polychemotherapy $\left(400 \mathrm{mg} / \mathrm{m}^{2}\right.$ cyclophosphamide daily, $15 \mathrm{mg} / \mathrm{m}^{2}$ cisplatin daily and $40 \mathrm{mg} /$ $\mathrm{m}^{2}$ etoposide daily as a $24 \mathrm{~h}$ infusion, with all three drugs administered on days 1-4; plus $40 \mathrm{mg}$ dexamethasone intravenously daily on days $1-4)$ and $2(4.7 \%)$ did not receive any treatment. The clinical responses were as follows: 9 patients (20.9\%) achieved complete response (alkylating agents, $n=4$; thalidomide, $\mathrm{n}=5), 16(37.2 \%)$ achieved partial response (alkylating agents, $n=7$; thalidomide, $n=5$; bortezomib, $n=3$; infusional polychemotherapy, $n=1), 9$ (20.9\%) achieved very good partial response (alkylating agents, $n=4$; thalidomide, $\mathrm{n}=2$; bortezomib, $\mathrm{n}=2$; infusional polychemotherapy, $\mathrm{n}=1$ ), $3(7 \%)$ exhibited stable disease (alkylating agents, $n=2$; 
Table IV. Percentage of patients with methylated genes and expressed in activity and remission.

\begin{tabular}{lcrcc}
\hline Gene & $\begin{array}{c}\text { Methylated } \\
\text { in activity }\end{array}$ & $\begin{array}{c}\text { Methylated } \\
\text { in remission }\end{array}$ & $\begin{array}{c}\text { Expressed } \\
\text { in activity }\end{array}$ & $\begin{array}{c}\text { Expressed } \\
\text { in remission }\end{array}$ \\
\hline & $\mathrm{n}(\%)$ & $\mathrm{n}(\%)$ & $\mathrm{n}(\%)$ & $\mathrm{n}(\%)$ \\
P16 & $17(53)$ & $12(44)$ & $13(54)$ & $8(42)$ \\
P73 & $13(33)$ & $5(16)$ & $8(38)$ & $1(6)$ \\
E-cadh & $36(92)$ & $29(91)$ & $9(60)$ & $10(71)$ \\
SOCS-1 & $21(55)$ & $10(32)$ & $21(100)$ & $18(100)$ \\
SHP-1 & $24(60)$ & $25(71)$ & $12(80)$ & $10(71)$ \\
\hline
\end{tabular}

n, patient number; E-cadh, E-cadherin; SOCS-1, suppressor of cytokine signaling; $S H P-1$, Src homology region 2 domain-containing phosphatase- 1 .

bortezomib, $\mathrm{n}=1)$, and $4(9.3 \%)$ suffered progressive disease (alkylating agents, $\mathrm{n}=3$; bortezomib, $\mathrm{n}=1$ ). Clinical response was not evaluated in the two patients $(4.7 \%)$ who did not receive treatment.

Methylation status of the promoters and expression of the genes P16, SOCS-1, E-cadherin, p73 and SHP-1. Methylation status of the promoters and expression of the genes being assessed during active disease and remission were compared. The percentage of promoter methylation for each gene at the two time points is presented in Fig. 1. The behavior of both measures at these two different stages of the disease was similar with the exception of the methylation status of SOCS-1. For 9 patients (29\%), SOCS-1 was methylated during active disease but not in remission, and in 1 patient (3.2\%) SOCS-1 was methylated in remission but not during active disease $(\mathrm{P}=0.021)$. The methylation status of the promoters of the genes was not correlated with their expression $(\mathrm{P}>0.05)$. The number of samples tested and the percentage of methylation for each gene are indicated in Table IV.

Association of clinical variables with gene methylation or expression status. Amyloidosis was present in 4 patients (16.67\%) without $P 16$ expression during the active disease phase, but in none of the patients expressing P16 during the active phase $(\mathrm{P}=0.031)$. Differences in promoter methylation status of P16 and SOCS- 1 were observed with regard to ISS grade. The percentage of patients with methylated $P 16$ at remission increased according to severity grade: ISS I, 0 patients (0\%); ISS II, 5 patients (20\%); and ISS III, 6 patients (24\%) $(\mathrm{P}=0.027)$. In addition, the percentage of patients exhibiting methylated SOCS-1 during advanced stage active disease, ISS III, was 6 patients (16.67\%), double that of those at an early stage: ISS I, 3 patients $(8.33 \%$; $\mathrm{P}=0.037)$. The probability of survival until the time of data analysis was associated with the methylation status of $P 16$ : Unmethylated $P 16,8$ patients (29.6\%); and methylated $P 16,2$ patients (7.41\%; $\mathrm{P}=0.058)$. The median OS of the group with methylated and unmethylated $P 16$ was 23 vs. 34 months, respectively $(\mathrm{P}=0.04)$, and the median PFS was 21 vs. 36 months, respectively $(\mathrm{P}=0.003)$. SHP-1 methylation during active disease was associated with

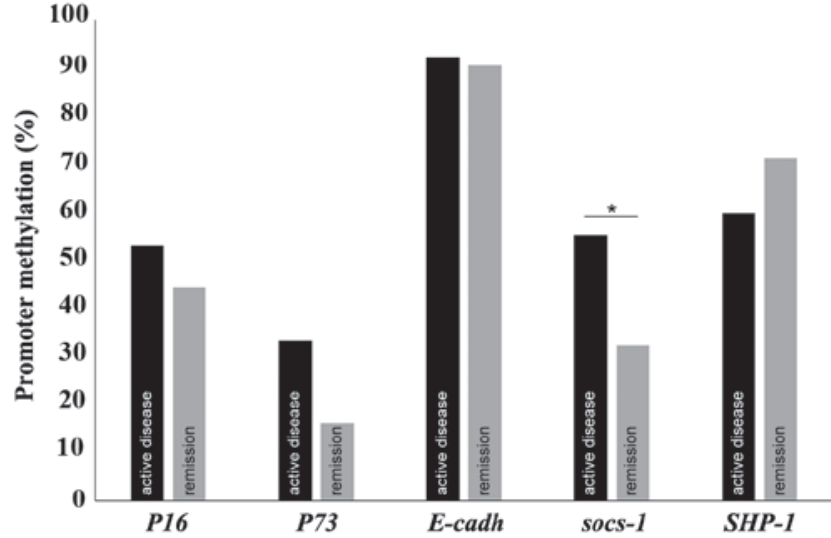

Figure 1. Promoter methylation during active disease and remission. The percentage of promoter methylation for each gene at the two time points, active disease (black) and remission (grey), is indicated. SOCS-1, suppressor of cytokine signaling; SHP-1, Src homology region 2 domain-containing phosphatase-1; E-cadh, E-cadherin. ${ }^{*} \mathrm{P}<0.05$.

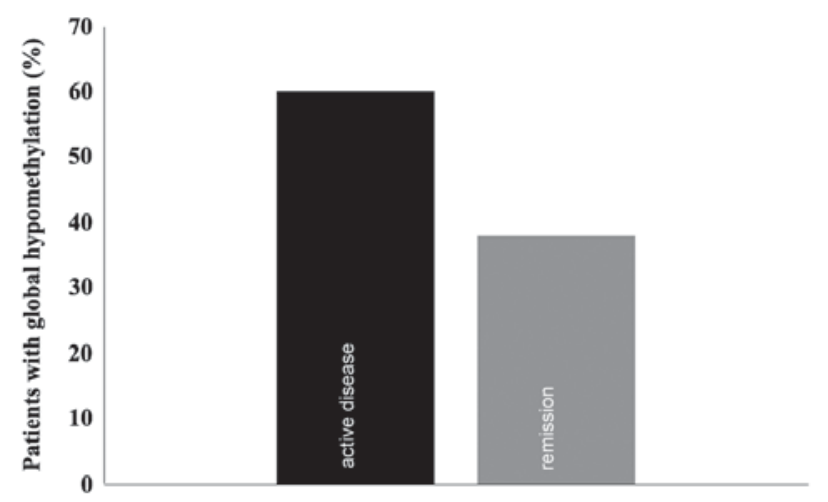

Figure 2. Global hypomethylation during active disease and remission. The percentage of patients with hypomethylation levels at active disease (black) and remission (grey) is indicated.

a lower probability of survival at 39-month follow up, with a median of 52.5 vs. $87.5 \%(\mathrm{P}=0.025)$. Methylation status did not affect gene expression.

Global methylation. A Global methylation assay was conducted in patients with available DNA once the MS-PCR assays were concluded $(n=15)$. The mean percentages of global methylation during active disease and remission were 14.26 and $13.83 \%$ respectively, with standard deviations of 21.48 [95\% confidence interval (CI), 2.814-25.713] and 10.72 (95\% CI, 8.115-19.549), respectively, which were not significantly different. The median of global methylation was $8.78 \%$ (range; 0.41-88.34\%; Fig. 2). There was a trend towards a moderate positive correlation between both variables, with a Spearman's relation coefficient of $0.494(\mathrm{P}=0.051)$.

Patient survival measures. The median OS for all patients was 53 months (95\% CI, 43.55-62.44; Fig. 3A). Following univariate analysis, the variables that were identified as relevant for OS included the presence of hypercalcemia, lytic bone lesions and global hypomethylation at remission (Table V). Following 
Table V. Univariate and multivariate analyses of variables associated with overall and progression free survival.

\begin{tabular}{|c|c|c|c|c|c|c|}
\hline \multirow[b]{2}{*}{ Variable } & \multicolumn{3}{|c|}{ Univariate } & \multicolumn{3}{|c|}{ Multivariate } \\
\hline & HR & $95 \% \mathrm{CI}$ & P-value & HR & $95 \% \mathrm{CI}$ & P-value \\
\hline \multicolumn{7}{|l|}{ Overall survival } \\
\hline Hypercalcemia & 1.322 & $1.020-1.715$ & $0.035^{\mathrm{a}}$ & 0.952 & $0.593-1.528$ & 0.838 \\
\hline Lytic bone lesions & 3.285 & $1.135-9.512$ & $0.028^{\mathrm{a}}$ & 5.992 & $0.837-42.890$ & 0.075 \\
\hline Global hypomethylation at remission & 3.866 & $1.117-13.374$ & $0.033^{\mathrm{a}}$ & 12.873 & $1.730-95.781$ & $0.013^{\mathrm{a}}$ \\
\hline \multicolumn{7}{|l|}{ Progression free survival } \\
\hline Hemoglobin & 0.837 & $0.722-0.970$ & $0.018^{\mathrm{a}}$ & 0.995 & $0.563-1.756$ & 0.985 \\
\hline Lactate dehydrogenase & 1.006 & $1.001-1.010$ & $0.013^{\mathrm{a}}$ & 1.017 & $0.961-1.077$ & 0.557 \\
\hline Lytic bone lesions & 4.795 & $1.373-16.753$ & $0.014^{\mathrm{a}}$ & 0.667 & $0.044-9.999$ & 0.769 \\
\hline Global hypomethylation at remission & 9.066 & $1.692-48.572$ & $0.010^{\mathrm{a}}$ & 7.258 & $0.255-206.821$ & 0.246 \\
\hline
\end{tabular}

${ }^{\mathrm{a}} \mathrm{P}<0.05 ; \mathrm{HR}$, hazards ratio; $\mathrm{CI}$, confidence interval.
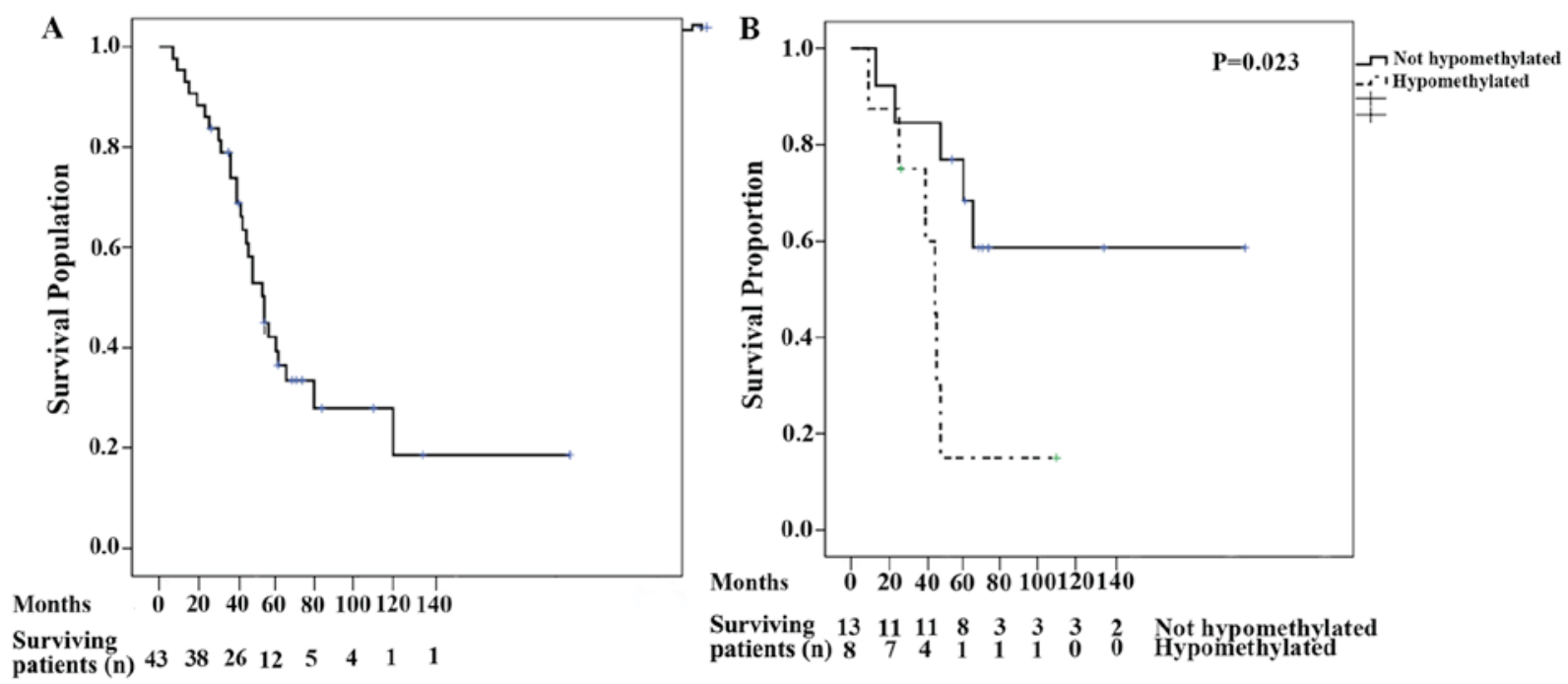

Figure 3. OS and OS associated with global methylation status at remission. (A) OS of the 43 patients. Median OS time was 53 months (95\% confidence interval, 43.55-62.44). (B) OS time according to global methylation status in remission. OS appeared to be worse when the status was hypomethylated (median, 44 months; $95 \%$ confidence interval, 31.70-56.29) vs. not hypomethylated (median not reached $>100$ months; $\mathrm{P}=0.012$ ). OS, overall survival.

multivariate analysis for OS, global hypomethylation at remission remained significant ( $\mathrm{P}=0.013$; Fig. 3B). The median PFS was 19 months (95\% CI, 9.94-28.06). Following univariate analysis, the variables identified to be relevant for PFS were hemoglobin, lactate dehydrogenase, presence of lytic bone lesions and global hypomethylation at remission. However, multivariate analysis for PFS indicated that none of the variables were significant (Table V).

\section{Discussion}

To the best of our knowledge, the present study is the first cohort of patients with MM utilized to study regional and global methylation during the active and remission disease phases. In the present study, genes previously reported to exhibit hypermethylation in MM were evaluated $(32,33)$. Overall, the results indicated that the methylation status of the promoters for the genes tested had no impact on the expression of these genes. However, the MS-PCR protocol utilized is only capable of analyzing two $\mathrm{CpG}$ sites at the $3^{\prime}$ ends of each of the two PCR primers, with the risk of involving noncrucial regions of the promoter essential for transcription (34). The methylation of different regions in a promoter have distinct potentials for suppressing promoter activity; therefore, certain sites may be more informative at predicting expression changes through direct functional interaction (35). SOCS-1 methylation was notably higher during active disease than at remission ( 29 vs. 3.2\%). A higher proportion of SOCS -1 methylation was observed in patients diagnosed with advanced stage MM at presentation (ISS III). By contrast, Depil et al (36) studied the methylation status of SOCS-1 in 51 untreated MM patients and identified hypermethylation of SOCS-1 in $74.5 \%$ of patients, with no influence on the clinical staging. SOCS-1 is able to suppress the signaling of different cytokines including interleukin 6, an important B-cell growth factor essential for differentiation into plasma cells and the survival rate of MM 
cells $(37,38)$. It has been identified that there is an association between hypermethylation of SOCS-1 and the pathogenesis of different tumors, including chronic myeloid leukemia, human melanoma and gastric cancer (39-41). A previous study by Galm et al (22), demonstrated that in patients with MM exhibiting active disease, $62 \%$ exhibited SOCS-1 hypermethylation. By contrast, this frequency was markedly lower in patients with lymphoma (3.2\%). Additionally, no methylation of SOCS-1 was observed in normal peripheral blood mononuclear cells or nonmalignant bone marrow cells. Furthermore, the present study identified that $P 16$ hypermethylation at remission occurred more frequently in patients with advanced disease (higher ISS grade) and indicated a trend toward patient mortality by the study cut-off point. Both results point to more aggressive behavior of the disease in patients with $P 16$ hypermethylation. P16, an inhibitor of cyclin dependent kinase 4, negatively regulates cell proliferation, which suggests that it exerts tumor suppressor behavior. A previous study by Mateos et al (41) assessed the methylation status of $P 16$ in a cohort of patients with MM and revealed that hypermethylation of $P 16$ was correlated with deleterious prognosis features including high $\beta 2$-microglobulin and high C-reactive protein values, advanced stage of disease according to the Durie-Salmon staging system and a high proliferation rate of plasma cells. The same study showed that none of the patients at stage I (Durie-Salmon) exhibited hypermethylation of $P 16$ (41). The present study suggested that $P 16$ hypermethylation negatively affected OS and PFS. However, when the high proliferation rate of PCs was incorporated into the multivariate analysis, $P 16$ hypermethylation lost its predictive value of both endpoints, implying an association between these variables. Guillerm et al (42) reported an association between methylated $P 16$ and $\mathrm{OS}(\mathrm{P}=0.035$; relative risk, 2.86, 1.076-7.60) and high $\beta 2$-microglobulin $(\mathrm{P}=0.003$; relative risk, 1.18, 1.08-1.3). Вy contrast, Gonzalez-Paz et al (3) did not identify any clinical or biological differences in patients with MM according to P16 methylation status with the exception of a higher frequency of $P 17$ deletion in the $P 16$ hypermethylated group (65\% vs. $35 \%, \mathrm{P}=0.003)$ and a trend in PFS in favor of the unmethylated group (median 30.2 vs. 27.4 months, $\mathrm{P}=0.71$ ).

Ribas et al (43) failed to detect a correlation between P16 methylation and prognostic factors. P16 hypermethylation has been associated with progression of the disease, as the frequency of this phenomena increases as the disease progresses through its different stages of evolution, beginning at $0 \%$ at the preclinical phase or monoclonal gammopathy of undetermined significance, at $0 \%$ for the asymptomatic phase, and to $41.8 \%$ for symptomatic MM and $80 \%$ for plasma cell leukemia $(3,4,20,21)$. In the current study, the probability of patients succumbing prior to the time of analysis was $56.2 \%$ (7 patients) if SHP-1 was not methylated during the active disease, whereas $12.5 \%$ (5 patients) of patients remained alive if $S H P-1$ was methylated at this point $(\mathrm{P}=0.025)$. $S H P-1$ encodes a member of the protein tyrosine phosphatase (PTP) family (44). PTPs oppose the effects of protein tyrosine kinases and maintain the overall homeostasis of protein tyrosine phosphorylation. It has been identified that PTPs dephosphorylate and thus inactivate Janus kinase/Signal transducer and activator of transcription 3 (STAT3) signaling. They regulate a variety of cellular processes including cell growth, differentiation, oncogenic transformation and the mitotic cycle. $S H P-1$ is expressed in normal lymphoid cells, but is lost in a number of types of hematologic malignancies due to epigenetic silencing $(45,46)$. It has been demonstrated that loss of $S H P-1$ directly contributes to the constitutive activation of STAT3 in MM, chronic myeloid leukemia and anaplastic lymphoma kinase-positive anaplastic large cell lymphoma (47). In the current study, the median OS was 53 months (95\% CI, 43.5-62.4). Following univariate analysis, hypercalcemia, presence of lytic bone lesions and global hypomethylation at remission were determined to have a negative impact on OS. The presence of lytic bone lesions implies a more advanced disease at the time of diagnosis. Global hypomethylation at remission remained a negative predictor for OS upon multivariate analysis. This raises the question of whether patients with global hypomethylation at remission should receive more treatment than patients without global hypomethylation. The assay was a commercially available ELISA, an inexpensive and widely used technique; therefore, prospective trials to measure methylation levels could readily be performed. In support of this possibility, Fernández de Larrea et al (48) reported the impact of global methylation in relapsed patients with MM treated with bortezomib. The study revealed that patients with $>3.95 \%$ global DNA methylation achieved an improved OS compared with lower levels of hypomethylation (median; 30 vs. 15 months, $\mathrm{P}=0.004$ ) (48).

Finally, it is important to emphasize that the OS and PFS of the patients in the current study were lower than expected according to those reported in other studies. These unsatisfactory outcomes may be due to limited access to expensive drugs (49-53). In this cohort, only $16 \%$ of the patients were able to receive bortezomib and none received lenalidomide.

To the best of our knowledge, the present study was the first to investigate the impact of regional methylation and global methylation in patients with MM over time in active and remission disease states. The number of patients included in the global methylation analysis was the primary limitation of the present study.

In conclusion, methylated $P 16, S O C S-1$ and $S H P-1$ are associated with clinical variables that negatively impact prognosis, along with the persistence of global hypomethylation at remission.

\section{Acknowledgements}

The authors would like to thank Dr Sergio Ponce de Leon for expert assistance with the statistical analysis. Déborah Martínez-Baños is a doctoral student from Programa de Doctorado en Ciencias Biomédicas, Universidad Nacional Autónoma de México (UNAM) and received a fellowship (SALUD-2007-C01-69695) from CONACYT that supported the present study.

\section{References}

1. Kyle RA and Rajkumar SV: Treatment of multiple myeloma: A comprehensive review. Clin Lymphoma Myeloma 9: 278-288, 2009.

2. Sonneveld P and Broijl A: Treatment of relapsed and refractory multiple myeloma. Haematologica 101: 396-406, 2016. 
3. Gonzalez-Paz N, Chng WJ, McClure RF, Blood E, Oken MM, Van Ness B, James CD, Kurtin PJ, Henderson K, Ahmann GJ, et al: Tumor suppressor p16 methylation in multiple myeloma: Biological and clinical implications. Blood 109: 1228-1232, 2007.

4. Mateos MV, García-Sanz R, López-Pérez R, Moro MJ, Ocio E, Hernández J, Megido M, Caballero MD, Fernández-Calvo J, Bárez A, et al: Methylation is an inactivating mechanism of the p16 gene in multiple myeloma associated with high plasma cell proliferation and short survival. Br J Haematol 118: 1034-1040, 2002.

5. Reik W, Dean W and Walter J: Epigenetic reprogramming in mammalian development. Science 293: 1089-1093, 2001.

6. Baylin SB, Esteller M, Rountree MR, Bachman KE, Schuebel K and Herman JG: Aberrant patterns of DNA methylation, chromatin formation and gene expression in cancer. Hum Mol Genet 10: 687-692, 2001.

7. Jones PL and Wolffe AP: Relationships between chromatin organization and DNA methylation in determining gene expression. Semin Cancer Biol 9: 339-347, 1999.

8. Fatemi M, Pao MM, Jeong S, Gal-Yam EN, Egger G, Weisenberger DJ and Jones PA: Footprinting of mammalian promoters: Use of a CpG DNA methyltransferase revealing nucleosome positions at a single molecule level. Nucleic Acids Res 33: e176, 2005.

9. Ahuja N and Issa JP: Aging, methylation and cancer. Histol Histopathol 15: 835-842, 2000.

10. Jones PA and Baylin SB: The epigenomics of cancer. Cell 128 : 683-692, 2007.

11. Berdasco $\mathrm{M}$ and Esteller M: Aberrant epigenetic landscape in cancer: How cellular identity goes awry. Dev Cell 19: 698-711, 2010.

12. Asmar F, Punj V, Christensen J, Pedersen MT, Pedersen A, Nielsen AB, Hother C, Ralfkiaer U, Brown P, Ralfkiaer E, et al: Genome-wide profiling identifies a DNA methylation signature that associates with TET2 mutations in diffuse large B-cell lymphoma. Haematologica 98: 1912-1920, 2013.

13. Sandoval J, Mendez-Gonzalez J, Nadal E, Chen G, Carmona FJ, Sayols S, Moran S, Heyn H, Vizoso M, Gomez A, et al: A prognostic DNA methylation signature for stage I non-small-cell lung cancer. J Clin Oncol 31: 4140-4147, 2013.

14. Esteller M: Cancer epigenomics: DNA methylomes and histone-modification maps. Nat Rev Genet 8: 286-298, 2007.

15. Portela A and Esteller M: Epigenetic modifications and human disease. Nat Biotechnol 28: 1057-1068, 2010.

16. Shen L, Kondo Y, Guo Y, Zhang J, Zhang L, Ahmed S, Shu J, Chen X, Waterland RA and Issa JP: Genome-wide profiling of DNA methylation reveals a class of normally methylated $\mathrm{CpG}$ island promoters. PLoS Genet 3: 2023-2036, 2007.

17. Issa JP and Kantarjian HM: Targeting DNA methylation. Clin Cancer Res 15: 3938-3946, 2009

18. Lee ES, Issa JP, Roberts DB, Williams MD, Weber RS, Kies MS and El-Naggar AK: Quantitative promoter hypermethylation analysis of cancer-related genes in salivary gland carcinomas: Comparison with methylation-specific PCR technique and clinical significance. Clin Cancer Res 14: 2664-2672, 2008.

19. Li H, Chiappinelli KB, Guzzetta AA, Easwaran H, Yen RW, Vatapalli R, Topper MJ, Luo J, Connolly RM, Azad NS, et al: Immune regulation by low doses of the DNA methyltransferase inhibitor 5-azacitidine in common human epithelial cancers. Oncotarget 5: 587-598, 2014.

20. González M, Mateos MV, García-Sanz R, Balanzategui A López-Pérez R, Chillón MC, González D, Alaejos I and San Miguel JF: De novo methylation of tumor suppressor gene p16/INK4a is a frequent finding in multiple myeloma patients at diagnosis. Leukemia 14: 183-187, 2000.

21. Krämer A, Schultheis B, Bergmann J, Willer A, Hegenbart U, Ho AD, Goldschmidt $\mathrm{H}$ and Hehlmann R: Alterations of the cyclin $\mathrm{D} 1 / \mathrm{pRb} / \mathrm{p} 16$ (INK4A) pathway in multiple myeloma. Leukemia 16: 1844-1851, 2002.

22. Galm O, Yoshikawa H, Esteller M, Osieka R and Herman JG: SOCS-1, a negative regulator of cytokine signaling, is frequently silenced by methylation in multiple myeloma. Blood 101: 2784-2788, 2003.

23. Chim CS, Liang R, Leung MH, Yip SF and Kwong YL: Aberrant gene promoter methylation marking disease progression in multiple myeloma. Leukemia 20: 1190-1192, 2006.

24. Amatori S, Bagaloni I, Donati B and Fanelli M: DNA demethylating antineoplastic strategies: A comparative point of view. Genes Cancer 1: 197-209, 2010.
25. Flotho C, Claus R, Batz C, Schneider M, Sandrock I, Ihde S, Plass C, Niemeyer CM and Lübbert M: The DNA methyltransferase inhibitors azacitidine, decitabine and zebularine exert differential effects on cancer gene expression in acute myeloid leukemia cells. Leukemia 23: 1019-1028, 2009.

26. Durie BG, Harousseau JL, Miguel JS, Bladé J, Barlogie B, Anderson K, Gertz M, Dimopoulos M, Westin J, Sonneveld $\mathrm{P}$, et al: International uniform response criteria for multiple myeloma. Leukemia 20: 1467-1473, 2006.

27. Draube A, Pfister R, Vockerodt M, Schuster S, Kube D, Diehl V and Tesch $\mathrm{H}$ : Immunomagnetic enrichment of CD138 positive cells from weakly infiltrated myeloma patients samples enables the determination of the tumor clone specific IgH rearrangement. Ann Hematol 80: 83-89, 2001.

28. Herman JG, Graff JR, Myöhänen S, Nelkin BD and Baylin SB: Methylation-specific PCR: A novel PCR assay for methylation status of CpG islands. Proc Natl Acad Sci USA 93: 9821-9826, 1996.

29. San Miguel J, Schlag R, Khuageva N, Dimopoulos M, Schpilberg O, Kropff M, Spicka I, Petrucci M, Palumbo A, Samoilova O, et al: Bortezomib plus melphalan and prednisone for initial treatment of multiple myeloma. N Engl J Med 359: 906-917, 2008

30. Richardson PG, Sonneveld P, Schuster MW, Irwin D, Stadtmauer EA, Facon T, Harousseau JL, Ben-Yehuda D, Lonial S, Goldschmidt H, et al: Bortezomib or high-dose dexamethasone for relapsed multiple myeloma. N Eng J Med 352: 2487-2498, 2005.

31. Greipp PR, San Miguel J, Durie BG, Crowley JJ, Barlogie B, Bladé J, Boccadoro M, Child JA, Avet-Loiseau H, Kyle RA, et al: International staging system for multiple myeloma. J Clin Oncol 23: 3412-3420, 2005.

32. Guillerm G, Depil S, Wolowiec D and Quesnel B: Different prognostic values of p15(INK4b) and p16(INK4a) gene methylations in multiple myeloma. Haematologica 88: 476-478, 2003.

33. Galm O, Wilop S, Reichelt J, Jost E, Gehbauer G, Herman JG and Osieka R: DNA methylation changes in multiple myeloma. Leukemia 18: 1687-1692, 2004

34. Deng G, Chen A, Hong J, Chae HS and Kim YS: Methylation of $\mathrm{CpG}$ in a small region of the hMLH1 promoter invariably correlates with the absence of gene expression. Cancer Res 59: 2029-2033, 1999.

35. Deng G, Chen A, Pong E and Kim YS: Methylation in hMLH1 promoter interferes with its binding to transcription factor $\mathrm{CBF}$ and inhibits gene expression. Oncogene 20: 7120-7127, 2001.

36. Depil S, Saudemont A and Quesnel B: SOCS-1 gene methylation is frequent but does not appear to have prognostic value in patients with multiple myeloma. Leukemia 17: 1678-1679, 2003.

37. Kyle RA and Rajkumar SV: Multiple myeloma. N Engl J Med 351: 1860-1873, 2004

38. Roman-Gomez J, Jimenez-Velasco A, Castillejo JA, Cervantes F, Barrios M, Colomer D, Heininger A and Torres A: The suppressor of cytokine signaling-1 is constitutively expressed in chronic myeloid leukemia and correlates with poor cytogenetic response to interferon-alpha. Haematologica 89: $42-48,2004$

39. Li Z, Metze D, Nashan D, Müller-Tidow C, Serve HL, Poremba C, Luger TA and Böhm M: Expression of SOCS-1, suppressor of cytokine signalling-1, in human melanoma. J Invest Dermatol 123: 737-745, 2004.

40. Qu Y, Dang S and Hou P: Gene methylation in gastric cancer. Clin Chim Acta 424: 53-65, 2013.

41. Mateos MV, Garcia-Sanz R, López-Pérez R, Balanzategui A, González MI, Fernández-Calvo J, Moro MJ, Hernández J, Caballero MD, González M and San Miguel JF: p16/INK4a gene inactivation by hypermethylation is associated with aggressive variants of monoclonal gammopathies. Hematol J 2: 146-149, 2001

42. Guillerm G, Depil S, Wolowiec D and Quesnel B: Different prognostic values of p15 (INK4b) and p16 (INK4a) gene methylations in multiple myeloma. Haematologica 88: 476-478, 2003.

43. Ribas C, Colleoni GW, Felix RS, Regis Silva MR, Caballero OL, Brait M and Bordin JO: p16 gene methylation lacks correlation with angiogenesis and prognosis in multiple myeloma. Cancer Lett 26: 247-254, 2005 .

44. Chim CS, Fung TK, Cheung WC, Liang R and Kwong YL: SOCS1 and SHP1 hypermethylation in multiple myeloma: Implications for epigenetic activation of the Jak/STAT pathway. Blood 103: 4630, 2004 
45. Esposito N, Colavita I, Quintarelli C, Rodeo A AL Peluso Luciano L, Picardi M, Vecchio L, Buonomo T and Hughes T: SHP-1 expression accounts for resistance to imatinib treatment in Philadelphia chromosome-positive cells derived from patients with chronic myeloid leukemia.

46. Valentino L and Pierre J: JAK/STAT signal transduction: Regulators and implications in hematological malignancies. Biochem Pharmacol 71: 713-721, 2006.

47. Zhang HF and Lai R: STAT3 in cancer-friend or Foe? Cancers (Basel) 6: 1408-1440, 2004.

48. Fernández de Larrea C, Martín-Antonio B, Cibeira MT,Navarro A Tovar N, Díaz T, Rosiñol L, Monzó M, Urbano-Ispizua A and Bladé J: Impact of global and gene-specific DNA methylation pattern in relapsed multiple myeloma patients treated with bortezomib. Leuk Res 37: 641-646, 2013.

49. Homedes $\mathrm{N}$ and Ugalde A: Availability and affordability of new medicines in Latin American countries where pivotal clinical trials were conducted. Bull World Health Organ 93: 674-683, 2015.

50. Pichon-Riviere A, Garay OU, Augustovski F, Vallejos C, Huayanay L, Bueno Mdel P, Rodriguez A, de Andrade CJ, Buendía JA and Drummond M: Implications of global pricing policies on access to innovative drugs: The case of trastuzumab in seven Latin American countries. Int J Technol Assess Health Care 31: 2-11, 2015.
51. Goss PE, Lee BL, Badovinac-Crnjevic T, Strasser-Weippl K, Chavarri-Guerra Y, St Louis J, Villarreal-Garza C, Unger-Saldaña K, Ferreyra M, Debiasi M, et al: Planning cancer control in Latin America and the Caribbean. Lancet Oncol 14: 391-436, 2013.

52. Amador-Medina LF, Lacayo-Leñero D, Crespo-Solís E, Aguayo Á and Martínez-Baños D: Thalidomide and dexamethasone induction therapy until best response in recently diagnosed patients with multiple myeloma: Results from a pilot study. Rev Invest Clin 67: 304-312, 2015.

53. Knaul FM, González-Pier E, Gómez-Dantés O, García-Junco D, Arreola-Ornelas H, Barraza-Lloréns M, Sandoval R, Caballero F, Hernández-Avila M, Juan M, et al: The quest for universal health coverage: Achieving social protection for all in Mexico. Lancet 380: 1259-1279, 2012 